\title{
Monitoring and Control of Pressure and Flow in Oil Pipeline Transport System
}

\author{
Abinethri R , B.Kalaiselvi, T.Vijayan
}

\begin{abstract}
In this paper, a PLC based PID controller is planned. $B y$ executing PLC and SCADA, the programmed controlling and observing assumes a significant job for the persistent activity of the framework. It directs the stream pace of the oil based goods naturally at the goal endpoint by controlling the stream and weight flag in the long transmitting pipeline framework. PLC based controller is created and their shut circle reaction is distinguished, and the recreation is completed to guarantee the presentation of the controller. SCADA screen screens the continuous information of stream and weight which is utilized in information logging.The results got from ongoing demonstrates that PID controller furnishes elite with least time delay. PID controller on maintaining stream at a predefined extend by embedding various weights as controlled factors. [1],[ 3],[5]

Keywords : PLC, SCADA, PID Controller.
\end{abstract}

\section{INTRODUCTION}

By actualizing control valves the parameters like weight and stream are kept up continually upon the diverse weight and stream pace of the transmitting channel. PLC (Programmable Logical Controller) directs naturally the stream and weight during oil based good transportation by managing the level of opening of the control valves individually. A reasonable controller is actualized to direct a long transmitting pipeline framework for a required set purpose of stream rate and weight. This, a PLC-based PID controller is created and its shut circle reactions are distinguished. [2 ],[4],[6]

The get together of control valve comprises of the inside trim parts, valve body, an actuator to give the thought process capacity to work the valve, and an assortment of extra valve frill, which can incorporate transducers, supply weight controllers, manual administrators, Snubber or point of confinement switches. Here globe type control valve is utilized and stream is considered as a last control component.

The stream parameter is controlled with the characterized set point, and by PID controller for the controller activity. PID controller gets the sign stream data from the stream transmitter. This will be passed as the last control component to the to the control valve. An uncommon direct structure is introduced with sensors will screen and control stream and weight on pipelines. They showed a multilayer correspondence plots that guarantee the successful directing of information among the sensors however there is no thought of control valve among the sensor based remote correspondence systems which includes manual activity to accomplish wanted execution of pipeline transportation. [7], [ 9], [11]

\section{METHODOLOGY}

With the utilization of SCADA screen the ongoing observing of the whole constant framework reveling of 3 weight sensors, one stream sensor and the last control component i.e., the control valve. The information logging is finished utilizing the most recent pattern of utilizing IOT and HART correspondence. This is done to know the different status of the field gadgets and remote terminal units. This procedure ought to be completely secure with expectant control framework since it includes inflammable fuel. To upgrade the working of the framework in a protected zone we utilize ongoing innovation of HART correspondence and IOT. This will decrease the disappointments and debacles in a brilliant manner. [8],[ 10],[12]

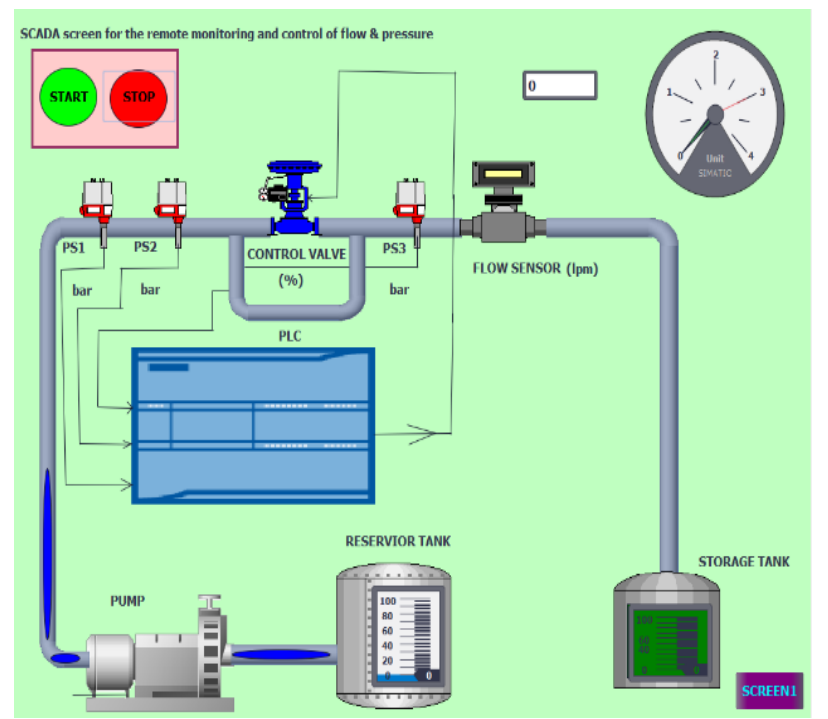

Fig1: SCADA screen for monitoring and controlling of flow and pressure
Revised Manuscript Received on August 22, 2019.

R.Abinethri, Department of EIE, Bharath Institute of Higher education and research, Tamilnadu, India. Email: abi.eie@ bharathuniv.ac.in

B.Kalaiselvi, Department of EIE, Bharath Institute of Higher education and research, Tamilnadu, India. Email: kalaiselvi.eie@bharathuniv.ac.in

T.Vijayan, Department of EIE,Bharath Institute of Higher education and research, Tamilnadu, India. Email: vijayan.eie@bharathuniv.ac.in 


\section{PROGRAMMABLELOGIC}

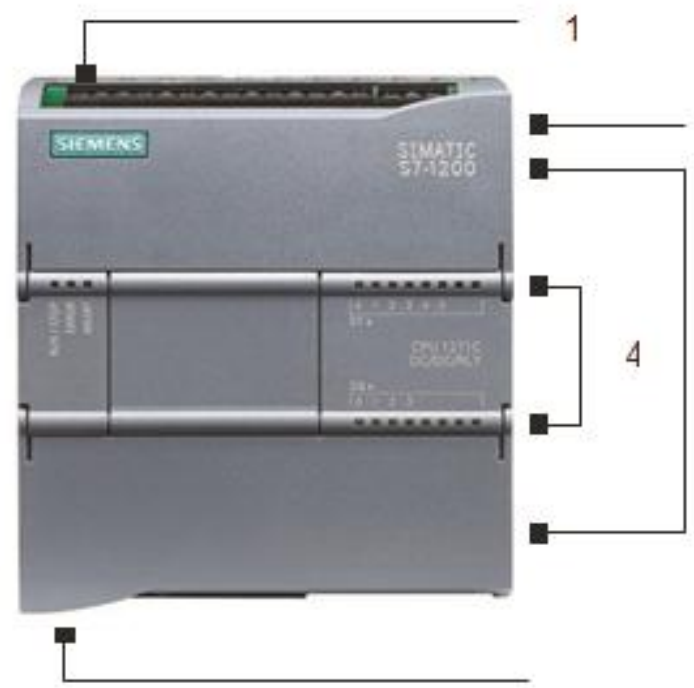

Fig 2: Siemens S7 - 1200 controller

Power connector

2. Memory card slot

3. Removable user

4. Status LEDs for

Siemens S7-1200 has adaptable setup, amazing guidance set and the compact structure gives adaptability and capacity to control a wide assortment of utilizations. To have an amazing controller CPU has a processor, control supply, I/O circuits, inbuilt PROFINET, fast movement control information and yield, and on-board simple contributions to a smaller lodging. Complex math tasks and correspondence with other savvy gadgets should be possible through CPU as indicated by the rationales characterized by the client.

To have correspondence over PROFINET organize, a PROFINET port has been given by the CPU. Extra modules like GPRS, RS485 or RS232 are additionally accessible.

\section{PRESSURE SENSOR}

Differential Pressure (DP), Gauge Pressure (GP) and Absolute Pressure (AP) estimations are finished by The Rosemount 3051C coplanar plan and it utilizes capacitance sensor innovation for DP and GP estimations. The Rosemount $3051 \mathrm{~T}$ for Piezoresistive sensor innovation and 3051C AP estimations. The real parts are sensor module which has the oil filled sensor framework (separating stomachs, oil fill framework, and sensor) and the hardware lodging

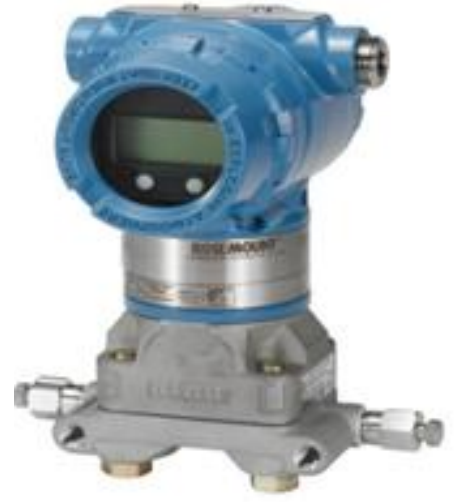

Fig 3: Rosemount 3051C pressure sensor

\section{FLOW SENSOR}

The Rosemount 8732E stream transmitter offers top tier execution combined with cutting edge diagnostics to give unrivaled procedure the board abilities. With numerous symptomatic suites accessible, the Rosemount $8732 \mathrm{E}$ gives clients the devices required to exceptionally precise sign preparing for liquids that are going somewhere in the range of 0.04 and $39 \mathrm{ft} / \mathrm{s}(0.01$ to $12 \mathrm{~m} / \mathrm{s})$ for both forward and invert stream in all stream tube sensor sizes. [13], [15] , [17]

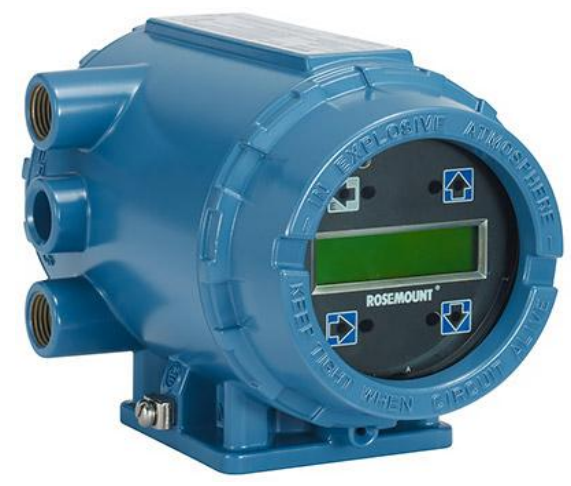

Fig 4: Rosemount 8732E flow

\section{CONTROL VALVE}

Fundamentally, a globe kind of control valve comprises of two sections as pursues:

Main (globe) valve body

Diaphragm kind of pneumatic actuator

This two-valve's part is coupled by an uncommon coupling, when the gaseous tension coming into the stomach pneumatic actuator the elastic stomach inside the actuator will push or force the principle (globe) valve stem/shaft descending or upward. The primary plan of this control valve is globe type, a valve with a straight up-down sort of development to open/close the liquid stream and the body shape is globular with a fitting circle as the fundamental part inside it. The voyaging direct up-down separations of the valve is called valve's stroke. Since the principle valve will constantly open with a certain $\%$ of opening. It will make

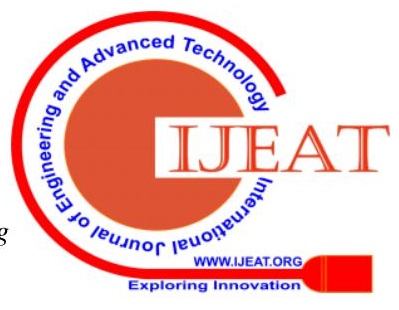


a differential weight $(\Delta \mathrm{P}=$ Delta $\mathrm{P}=\mathrm{P} 1-\mathrm{P} 2)$ between the bay and outlet of the valve

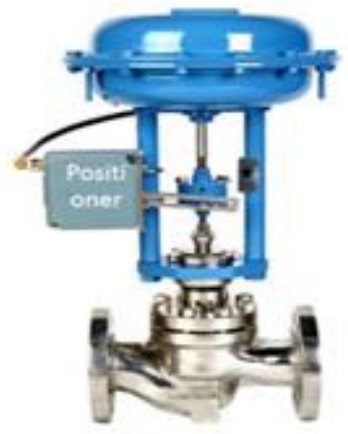

Fig 5: Control valve

\section{STORAGE TANK}

Gliding rooftop oil tanks is comprised of a round and hollow steel shell which has a drifting rooftop that buoys over the fluid in the tank. The situation of the rooftop relies on the degree of raw petroleum in the tank. At the point when there is increasingly unrefined petroleum, the rooftop rises and the other way around when the level is low.

To store enormous amounts of raw petroleum, drifting tanks are considered as best decision. The edge seal on the skimming rooftop tank has the discharges from the raw petroleum that produces unstable gaseous petrol just as some air contaminations that has been discharged to the earth. These emanations are a great idea to be contained since they may create flames and blasts. Contingent on the decision of the client, it is conceivable to catch the vapor so it isn't lost and that can be neither used at the plant where unrefined petroleum is put away nor would it be able to be stuffed available to be purchased to invested individuals.

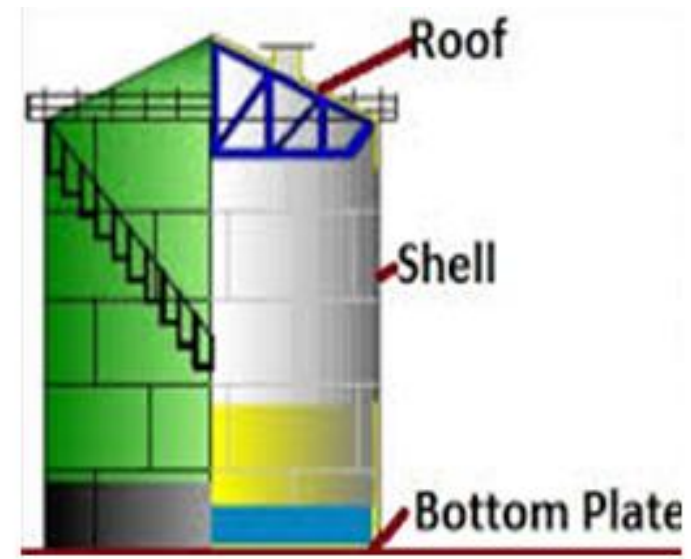

Fig 6: Floating roof tank

\section{PIPELINES}

The preparing, transportation and capacity of oil is profoundly mind boggling with high weight and consumption.

Unrefined petroleum from the underground contains substances, for example, sulfur and hydrogen sulfide that can oxidize the pipeline. This is a key issue during the oil transportation. In this manner, the material picked must address these issues. Steel is the most utilized material applied in the oil moving and capacity. Some method has been created to build its quality and its consumption obstruction. Steel channels are long, empty cylinders. As indicated by measurements, there are a huge number of huge amounts of dark steel pipe being delivered every year, they are so adaptable and in this manner generally utilized in numerous ventures. It's not hard to find that steel channels are utilized in a many spot. Since they are intense and hard, they are utilized for moving oil, gas, water all through urban communities and towns. They can be lightweight despite the fact that they are hard. Dark pipe, a type of dark steel pipe, was broadly utilized in homes worked before the 1960s.But since dark funnels are solid, they are as yet utilized for applications like gas and oil line. The dark appearance is framed by a dark oxide scale when fashioning the steel pipe[14],[16], [18]
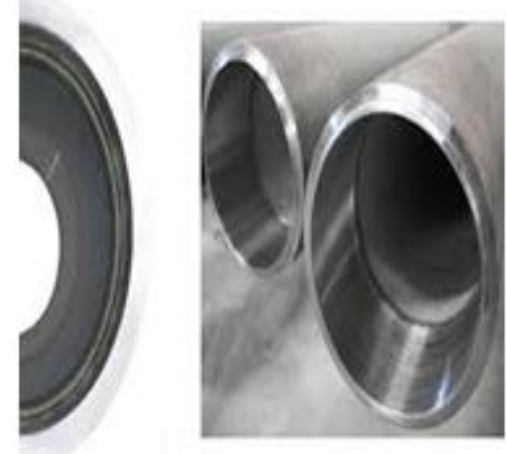

Fig 7: Steel pipe

\section{IX.PUMP}

The siphons are made of duplex tempered steel and every one has a stream pace of 2,000 cubic meters for each hour. The head is around 80 meters. During testing, both siphon and engine surpassed the cited efficiencies. The oil will be siphoned to the surface by three extraordinary planned submersible borehole siphon. Each of the three siphons are furnished with a $700-\mathrm{kW}$ engine and are worked at a voltage of $6,600 \mathrm{~V}$.

Diffusive siphons are widely utilized in the oil and gas enterprises and the siphon execution drops with higher thickness and higher surface harshness of the siphon impeller, and the impeller structure parameters have noteworthy impact on the siphon execution. The impeller is the turning some portion of the siphon and the packaging is the water/air proof entry which encompasses the impeller. In a divergent siphon, liquid goes into the packaging, falls on the impeller edges at the eye of the impeller, and is spun digressively and radially outward until it leaves the impeller into the diffuser piece of the packaging. While going through the impeller, the liquid is increasing both speed and weight. Radial Pumps are valuable since they can for the most part handle huge amount of liquids, give high stream rates and can change their stream rates over a wide run.

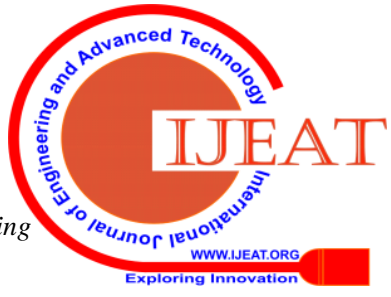




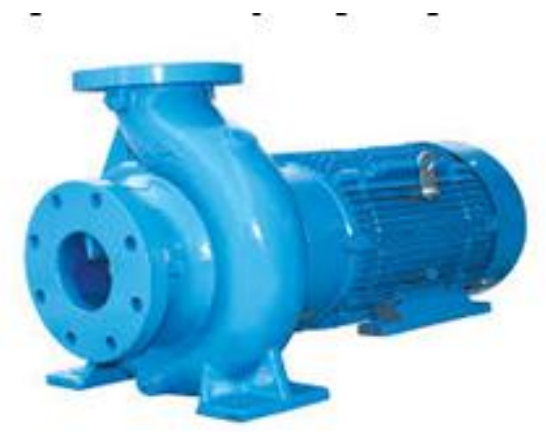

Fig 8: Centrifugal pump

\section{SOFTWARESIMULATION}

Programming utilized are,SCADA WinCC Rt Advanced In enormous mechanical foundations many procedure happen all the while and every should be checked, which is really a complex task.The SCADA frameworks are utilized to screen and control the gear's in the modern procedures which incorporate water circulation, oil conveyance and power appropriation. The principle point of this venture is to process the ongoing information and control the enormous scale remote mechanical condition. In the constant situation, a temperature logging framework for a remote plant activity is taken

\section{EXPERIMENTAL RESULTSAND DISCUSSION}

The elaboration of the control rationale in the Programmable Logic Controller (PLC), the information base and the operational screens of the supervisory framework. At the point when a control valve is introduced in a pipeline, it is important to discover the response it causes in the stream rate and weight. For every pipeline, these responses are extraordinary, regardless of whether comparative valves are used.Thus, it was important to recreate the inclusion of this valve in the framework, just as to perform field tests to affirm the consequences of the reproduction and to discover the control parameters of the valve, which are utilized for programming the PLC.

The tests have three principle destinations:

- To check if the valves react accurately to the directions given in the supervisory framework.

- To check which valve opening rate compares to which weight esteem and to decide the procedure adjustment time.

- These information feed the controller, which utilize a strategy dependent on the numerical calculation PID (Proportional, Integral and Derivative).

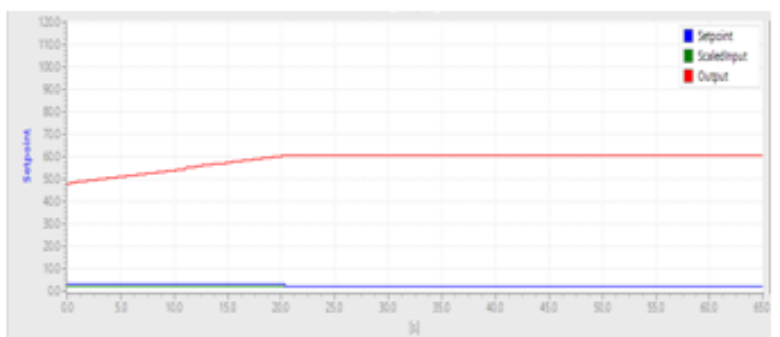

Fig 9: PID closed loop Response for Control valve output for $50 \%$ Set Point

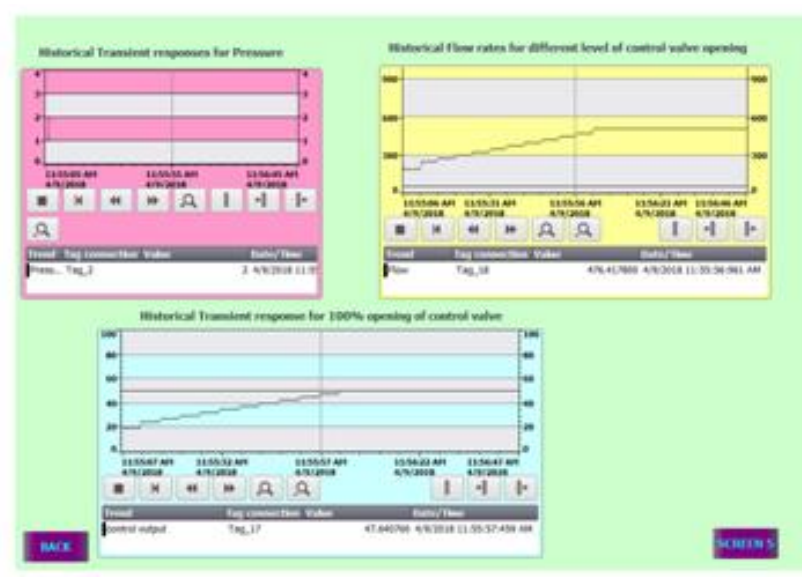

Fig 10: SCADA monitor showing the system running performance

After the implementation of this project, the pipeline is centrally controlled by PID. It is now ready for implementing the control of pressure and flow in oil pipelines transport system. The response in the line to any pressure or flow alteration is immediate and is monitored by the measurement system.

\section{CONCLUSION}

The execution of the venture introduced was a test for the group that was in charge of it, since the entire working way of thinking should have been changed. These progressions comprised in the adjustment of the equipment's, with the presentation of the siphons robotization and the addition of control valves in the goal. Moreover, PID controller strategy was expounded so as to qualify them to the new operational needs and to the fundamental conduct change.

The operational wellbeing is upgraded by the full pipeline activity, since any unsettling influence in the process is instantly seen by the supervisory framework (SCADA). SCADA is utilized for wide regions, long pipelines, incorporated telecoms, bookkeeping of item streams, and trade among end clients.

\section{REFERENCES}

[1] Sharma, R.K., Irusapparajan, G. \& Periyaazhagar, D. 2019 "Three-phase symmetric cascading Z-source seven levels multilevel inverter excited by multi carrier sinusoidal pulse width modulation scheme", International Journal of Innovative Technology and Exploring Engineering, vol. 8, no. 10, pp. 4269-4274. 
[2] Velavan, R., Bharanidharan, S. \& Sheeba, B. 2019, "EMF pollution Causes, effects and protection", International Journal of Innovative Technology and Exploring Engineering, vol. 8, no. 9 Special Issue 3, pp. 1166-1168.

[3] Saravana, S., Balaji, S., Arulselvi, S. \& John Paul Praveen, A. 2019 "Reliable power quality monitoring and protection system", International Journal of Innovative Technology and Exploring Engineering, vol. 8, no. 9 Special Issue 3, pp. 644-645.

[4] Tamil Selvan, S. \& Sundararajan, M. 2019, "Performance Parameters of 3 Value 8t Cntfet Based Sram Cell Design Using H-Spice", International Journal of Recent Technology and Engineering, vol. 8, no. 2 Special issue 5, pp. 22-27.

[5] Jac Fredo, A.R., Abilash, R.S., Femi, R., Mythili, A. \& Kumar, C.S 2019, "Classification of damages in composite images using Zernike moments and support vector machines", Composites Part B: Engineering, vol. 168, pp. 77-86

[6] Kathiravan, P. \& Govindaraju, C. 2019, "Design and evaluation of ultra gain isolated DC-DC converter for photovoltaic system", International Journal of Engineering and Advanced Technology, vol. 8, no. 5, pp. 2646-2651.

[7] Kripa, N., Vasuki, R. \& Kishore Kanna, R. 2019, "Realtime neural interface controlled au-pair BIMA bot", International Journal of Recent Technology and Engineering, vol. 8, no. 1, pp. 992-994.

[8] Mohanraj, Meenaa Kumari, M., Philomina, S. \& Jasmin, M. 2019 , "In-situ humidity measurement of hydrogen fuel cell car using MEMS sensor", International Journal of Recent Technology and Engineering, vol. 8 , no. 1, pp. 41-43.

[9] Velmurugan, T. \& Prakash, S. 2019, "Artificial intelligent based distribution automation of swift fault detection isolation and power restoration for HT network", International Journal of Innovative Technology and Exploring Engineering, vol. 8, no. 6, pp. 1-6.

[10] Dwarakesh, K. \& Prem Kumar, G. 2019, "Five-level inverter based sequential boost system using fuzzy logic controller", International Journal of Innovative Technology and Exploring Engineering, vol. 8, no. 6, pp. 12-19.

[11] Anne Gifta, A. \& Hemavathi, G. 2019, "Analysis of grid tied solar PV system using ANFIS Algorithm", International Journal of Innovative Technology and Exploring Engineering, vol. 8, no. 6, pp. 312-316.

[12] Jayavel, R., Rangaswamy, T.R. \& Prakash, S. 2019, "Efficient grid management system with renewable and conventional power sources", International Journal of Innovative Technology and Exploring Engineering, vol. 8, no. 6, pp. 287-289.

[13] Hemavathi, G. \& Maheshwaran, S. 2019, "Proportional resonant controlled high gain step-up converter system with improved response", International Journal of Innovative Technology and Exploring Engineering, vol. 8, no. 6, pp. 317-323.

[14] Periyaazhagar, D. \& Irusapparajan, G. 2019, "Design and completion of asymmetric single phase 27 level cascaded mli for various pwm scheme", International Journal of Innovative Technology and Exploring Engineering, vol. 8, no. 6, pp. 792-797.

[15] Mahalakshmi, V. \& Vijayaragavan, S.P. 2019, "PV based power electronic converters for high voltage DC applications", International Journal of Recent Technology and Engineering, vol. 7, no. 6, pp. 670-674.

[16] Irusapparajan, G., Periyaazhagar, D., Prabaharan, N. \& Rini Ann Jerin, A. 2019, "Experimental verification of trinary DC source cascaded h-bridge multilevel inverter using unipolar pulse width modulation", Automatika, vol. 60, no. 1, pp. 19-27.

[17] Sangeetha, G., Sherine, S., Arputharaju, K. \& Prakash, S. 2019, "On Line Monitoring of Higher Rated Alternator using Automated Generator Capability Curve Administer", Proceedings of the IEEE International Conference on \&amp;quot;Recent Trends in Electrical, Control and Communication\&amp;quot;, RTECC 2018, pp. 176.

[18] Bycil, V.J. \& Wiselin, M.C.J. 2019, "Modeling and analysis of vibration energy harvesting system using piezo stack", International Journal of Mechanical and Production Engineering Research and Development, vol. 9, no. Special Issue 1, pp. 523-533.

[19] Sripada, A., Warrier, A., Kapoor, A., Gaur, H. \& Hemalatha, B. 2018, "Dynamic lateral balance of humanoid robots on unstable surfaces", International Conference on Electrical, Electronics, Communication Computer Technologies and Optimization Techniques, ICEECCOT 2017, pp. 539

[20] Srinivasan, S., Thirumalaivasan, K. \& Sivakumaran, T.S. 2018, "Performance evaluation of double-output luo converters", Journal of Advanced Research in Dynamical and Control Systems, vol. 10, no. 10 Special Issue, pp. 870-878.

[21] Karthikayen, A. \& Selvakumar Raja, S. 2018, "A skellam distribution inspired trust factor-based selfish node detection technique in
MANETs", Journal of Advanced Research in Dynamical and Control Systems, vol. 10, no. 13, pp. 940-949.

\section{AUTHORS PROFILE}

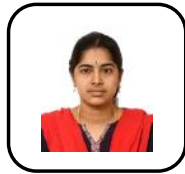

R.Abinethri, Assistant Professor, Department of EIE,Bharath Institute of Higher education and research, Tamilnadu, India

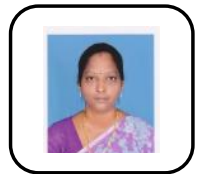

B.Kalaiselvi, Assistant Professor, Department of EIE,Bharath Institute of Higher education and research, Tamilnadu, India

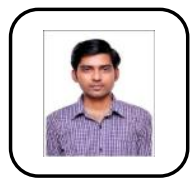

T.Vijayan, Assistant Professor, Department of EIE,Bharath Institute of Higher education and research, Tamilnadu, India. 